\title{
Anatomical Guide for Regional Anesthesia in the Buffalo in Egypt (Bos bubalis L.)
}

\author{
Farag, F.M., Daghash, S.M., El-Bably, S. H., Sary, R.G. and \\ Hagrass S.M. \\ Anatomy and Embryology Department, Faculty of Veterinary Medicine, Cairo University
}

With 9 figures $\quad$ Received October 2016, accepted for publication in April 2017

\section{Abstract}

The present study was conducted on eight buffaloes (Bos bubalis L.) of ages ranging between 2-7 years. The specimens were prepared by the routine anatomical methods used for fixing and manually dissected to expose the topographic arrangement of the nerves of flank and face of most clinical importance and commonly subjected to nerve block in cases of the surgical approaches to the flank as well as for the minute surgical operation in the head involving the nostrils, lips and horns. The definite site of injection of anesthetic drug was also suggested for each nerve. The study revealed that, the regional anesthesia of the mid paralumbar fossa in the buffalo was achieved through three distal paravertebral injections. The most cranial one for anesthesia of the costoabdominal nerve, at the upper part of the flank about $5 \mathrm{~cm}$ from the free end of the second lumbar transverse process and $7 \mathrm{~cm}$ caudal to the last rib and at a depth of about $3 \mathrm{~cm}$. The middle one for blocking the iliohypogastric was indicated $5 \mathrm{~cm}$ below the $3^{\text {rd }}$ lumbar transverse process midway between the last rib cranially and tuber coxae caudally, while the most caudal one for anesthesia of the ilioinguinal nerve inserts was applied about $5 \mathrm{~cm}$ cranial to the tuber coxae, $5 \mathrm{~cm}$ below the free end of the $4^{\text {th }}$ lumbar transverse process.

The infra-orbital, mental and cornual nerves were the most clinically important sensory nerves in the head region. For anesthesia of the infraorbital nerve the anesthetic drug was injected in the vicinity of the infraorbital foramen which was situated 1.5 $\mathrm{cm}$ dorsal to the first cheek tooth and about $6 \mathrm{~cm}$ rostral to the facial tubercle. For anesthesia of the mental nerve the needle was inserted at the middle distance of the lateral surface of the interalveolar space of the mandible between the lateral incisor and 


\section{Regional anesthesia in buffalo}

first premolar teeth. For anesthesia of the cornual nerve, the site of this regional block was midway between the orbital rim and the base of the horn, $4 \mathrm{~cm}$ medial to the frontal crest.

The results obtained were photographed, described and discussed with those of bovine species.

Keywords: Anatomy, Regional anesthesia, Buffalo,

\section{Introduction}

The Egyptian water buffalo (Bos bublis $L$ ) was a unique species of buffalo all over the world, which could accommodate different weather changes. Egypt had not less than 3 million water buffalos, which could solve feed problems from meat and milk. Buffalos constitute an important part of the array of domestic animal resources in Egypt and many other African countries (Bhatt, 1999; Wilson, 2012). The buffalos were descended from two distinct types, swamp buffalos and riverine buffalos. The riverine buffalos found mainly at the Mediterranean area from which the Egyptian buffalos were descended and they were hold for milk and meat production (Shalash, 1988; Soliman, 2009).

Due to their size and anatomy, cattle are not very good candidates for general anesthesia meaning that many procedures performed use the local
Farag et al.,

techniques. Most surgeries performed on these patients can be done standing with a small amount of sedation and regional nerve blocks (Edmondson, 2008). Several features of local anesthesia render it particularly useful in veterinary practice and many surgical procedures could be carried out satisfactorily under local anesthesia (Lee, 2006).

In buffalo, the available data about anesthetic techniques and surgical affections considered scarce. While in cattle, several methods of anesthesia for flank laparotomy have been described. In addition, each of them has some advantages and disadvantages for clinical use (Roberts, 1986; karda, 1996; Hall, et al., 2001). The present study is therefore an attempt to provide an anatomical guide indicating the accurate site of each nerve supplying the flank region, horns and lips in relation to bony prominences. Advantages of this approach: very easy when we know the morphometric study of the region, economic not consumes a large amount of anesthetic drug and in the same time more effective.

\section{Materials and Methods}

The present study was conducted on eight buffaloes (Bos bubalis L.) of ages ranging between $2-7$ years. Six of these animals were recently dead 
three of each sex and the remaining two animals were live one of each sex. The animals were collected from different area in Giza and transported to the laboratory of the Anatomy and Embryology Department Faculty of Veterinary Medicine, Cairo University. Both common carotid arteries were thoroughly flushed with warm $\left(40 c^{\circ}\right)$ saline solution and the specimens were then injected with formalin solution $(10 \%$ formalin, $4 \%$ phenol, $1 \%$ glycerin), and left to fix for 3-4 days then manually dissected to investigate the nerves under investigation. Measurements were applied using Vernier Calliper to indicated the accurate site of each nerve in relation to the nearest bony prominence to decide the best site for injection of the anaesthetic drug. The nerves were then coloured by acrylic colours and photographed.

The two live buffaloes were used for testing the anaesthetic effect after and the area of desensitization for each nerve under investigation. The animals were tranquilized by $10 \mathrm{mg} / \mathrm{kg}$ b.wt. Xylazine HCL 2\% (Xylaject HCL $2 \%$, Adwia Co. S.A.E.). The needle of 22 gauges was inserted into the indicated site for each nerve under investigation and $10-15 \mathrm{ml}$ of lidocaine HCL $2 \%$ (Debocaine HCL 2\%, Al-Debeiky Pharmaceutical Industry Co.-A.R.E) was injected and waited for 10 minutes for detection of the anesthetic drug effect.

The nomenclature used was adopted according to the Nomina Anatomica Veterinaria (2012).

\section{Results}

Regional anesthesia of the abdominal wall comprised 3 ventral rami of the last intercostal, first and second lumber nerves; namely the costoabdominal, iliohypogastric and ilioinguinal nerves respectively.

\section{$N$. costoabdominalis}

The costoabdominal nerve (Figs $1 / 1$ \& $2 / 2$ ), represented the ventral branch of the last intercostalis nerve. It descended in zigzag pattern in a ventrolateral direction with slight caudal inclination in the abdominal wall alongside the $\mathrm{M}$. transverses abdominis at a distance of about $6.0-7.0 \mathrm{~cm}$ caudal to the last rib. Near the ventral end of the last rib it divided into lateral and medial branches. The lateral branch penetrated the aponeuroses of the oblique abdominal muscles and distributed to the $\mathrm{M}$. cutaneous trunci and skin of the lateral abdominal wall. The medial branch distributed to the oblique abdominal muscles and terminated in the $M$. rectus abdominis as well as the skin of the ventral abdominal wall. The definite site for blocking the costoabdominal nerve 
(Fig 3/1) was indicated at the upper part of the flank about $5 \mathrm{~cm}$ below the free end of the second lumbar transverse process and $7 \mathrm{~cm}$ caudal to the last rib (Figs 1/2 \& 2/1) and at depth of about $3 \mathrm{~cm}$ penetrating the skin, fascia and oblique abdominal muscles. The desensitized area (Fig 3/4) comprised the cranial part of the flank and skin and fascia of the ventral abdominal wall.

\section{N. iliohypogastricus}

The lliohypogastric nerve (Figs $1 / 3$ \& $2 / 3$ ) constituted the ventral branch of the first lumbar spinal nerve. It descended in zigzag pattern in a ventrolateral direction with slight caudal inclination in the abdominal wall alongside the $\mathrm{M}$. transverses abdominis at the middle of the distance between the last rib and the tuber coxae (Fig 1/4) and divided at the level of the ventral end of the last rib into lateral and medial branches which followed the same course and distribution of the corresponding branches of the costoabdominal nerve. The accurate site for blocking the iliohypogastric (Fig 3/2) was indicated $5 \mathrm{~cm}$ below the $3^{\text {rd }}$ lumbar transverse process at the mid-distance between the last rib cranially and tuber coxae caudally, about 22-24 cm from each of the later two points at a depth $3 \mathrm{~cm}$. The desensitized area (Fig 3/5) comprised the middle part of both the flank ventral abdominal wall.

\section{$N$. Ilioinguinalis}

The llioinguinal nerve (Figs $1 / 5 \& 2 / 4$ ) represented the ventral branch of second lumbar spinal nerve. It descended in zigzag pattern in a ventrolateral direction with slight caudal inclination in the abdominal wall alongside the $M$. transverses abdominis at about $5 \mathrm{~cm}$ cranial to the tuber coxae. It divided on a level with the ventral end of the last rib into lateral and medial branches which followed the same course and distribution of the corresponding branches of the costoabdominal nerve. The accurate site for blocking the ilioinguinal nerve (Fig 3/3) was indicated at the upper part of the flank about 5 $\mathrm{cm}$ cranial to tuber coxae and about 5 $\mathrm{cm}$ below the $4^{\text {th }}$ lumbar transverse process. The area of destination (Fig $3 / 6$ ) of the ilioinguinal nerve comprised the skin and muscles in the caudal part of the lateral and ventral abdominal wall and to some extent front of the hip and thigh, lateral surface of the stifle, the skin of the external genital organs and the surrounding skin in the inguinal region and mammary gland (Fig 1/7).

Regional anesthesia was also applied in the head region and mostly involved the infraorbital, mental and cornual nerve block 


\section{N. infraorbitalis}

The infraorbital nerve (Fig 4/1) represented the continuation of the maxillary branch of the fifth cranial nerve after it enters the infraorbital canal. It emerged on the face as a flat band through the infraorbital foramen where it was covered by the levator nasolabialis muscle and soon divided into several rami that distributed to the nasal region and maxillary lip. For blocking the infraorbital nerve (Fig 9/1) the anesthetic drug was injected in the vicinity of the infraorbital foramen (Fig $5 / 3$ ) which was situated $1.5 \mathrm{~cm}$ dorsal to the first cheek tooth (Fig 5/2) and about $6 \mathrm{~cm}$ rostral to the facial tubercle (Fig 5/1). The drug was injected deep into the levator nasolabialis muscle and the injection should be repeated on the opposite side. The desensitized field (Fig 9/4) comprised the dorsum nasi and diverticulum nasi, the nasal vestibule as well as the maxillary lip.

\section{N. mentalis}

The Mental nerve (Fig 4/2) was a branch of the mandibular alveolar nerve that emerged via the mental foramen (Fig 6/2) and divided into three branches below the depressor anguli oris muscle These branches distributed to the skin of the chin as well as the skin and mucous membrane of the lower lip. For blocking of mental nerve (Fig 9/2) the needle was inserted in the vicinity of the mental foramen at the middle distance of the lateral surface of the interalveolar space of mandible between the lateral incisor (Fig 6/1) and first premolar teeth (Fig $6 / 3$ ) and the injection should be repeated on the opposite side. Injection of the drug rostral to the level of the mental foramen induced blocking of the mental nerve and the desensitized field (Fig 9/5) comprised the mandibular lip and chin without teeth or gum anesthesia. In another trial the needle was inserted in a rostro-caudal direction into the mental foramen and $10 \mathrm{ml}$ of the drug was injected deeply through the mandibular canal resulting in additional anesthesia of the mandibular cheek and incisor teeth and gum.

\section{N. cornualis}

The cornual nerve (Fig 7/1) emerged from the caudal opening of the supraorbital foramen (Fig 8/2) and proceeded caudolaterally in a special groove (Fig 8/3) reaching the base of the horn undercover of the $\mathrm{M}$. orbicularis oculi and $M$. frontalis. For blocking the cornual nerve, the agent was deposited subcutaneously midway between the orbital rim and the base of the horn $4 \mathrm{~cm}$ medial to the frontal crest (Fig $9 / 3)$. 


\section{Discussion}

According to Thomas and Lerche (2016) the anesthesia of the paralumbar fossa and abdominal wall in cattle can be achieved by several techniques. These techniques include the proximal paravertebral nerve block, the distal paravertebral nerve block, the inverted $L$ block and infusion of the incision or line block. These anesthetic techniques are commonly used for abdominal procedures such as omentopexy, abomasopexy, rumenotomy, cesarean section or other surgical approaches using a paralumbar fossa approach. The current investigation in buffalo indicated the accurate site for injection of anesthetic drug for each nerve supplying the flank region and aimed to consume smaller amount of anesthetic drug, produced fast action and in the same time more effective and also indicated the actual area innervated by each nerve. According to the present study the main nerves supplying the flank region were T13, L1 and L2. For anesthesia of the costoabdominal nerve (T13) bests site was indicated at the upper part of the flank about $5 \mathrm{~cm}$ from the free end of the second lumbar transverse process and $7 \mathrm{~cm}$ caudal to the last rib and at depth of about $3 \mathrm{~cm}$. The site for blocking the iliohypogastric (L1) was indicated $5 \mathrm{~cm}$ below the $4^{\text {th }}$ lumbar transverse process midway between the last rib cranially and tuber coxae caudally, about 22-24 cm from each of the later two points at depth $3 \mathrm{~cm}$. For anesthesia of ilioinguinal nerve (L2) the needle was inserted in the upper part of the flank about $5 \mathrm{~cm}$ cranial to tuber coxae and $5 \mathrm{~cm}$ below the $5^{\text {th }}$ lumbar transverse process. However, the indicated site for blocking each of these nerves could be compared favorably with the distal paravertebral anesthesia recommended by Edmondson (2008) and Thomas and lerche (2016). In this concern Vermunt (1999) reported that, for analgesia of the right and left paralumbar region, an area approximately $20 \mathrm{~cm}$ wide and $30 \mathrm{~cm}$ long should be prepared for aseptic surgery and analgesia provided by a line, an inverted 'L' or paravertebral block. The paracostal incision should be started 5 to $7.5 \mathrm{~cm}$ ventral to the transverse process of the second lumbar vertebrae and proceed ventrally and parallel to the last rib for about $20 \mathrm{~cm}$.

Edmondson (2008) added that, the inverted $\mathrm{L}$ block is a nonspecific regional block in cattle in which a 18gauge $3.8-\mathrm{cm}$ needle was used to inject up to a total of $100 \mathrm{ml}$ of local anesthetic solution in multiple small injection sites into the tissues bordering the dorsocaudal aspect of the thirteenth rib and ventrolateral aspect of the transverse processes of the lumbar vertebrae. The author also added that the disadvantages of this technique include incomplete analgesia 
and muscle relaxation of the deeper layers of the abdominal wall (particularly in obese animals); possible toxicity after larger doses of anesthetic; and increased cost because of larger doses of local anesthetic. Nuss et al (2012) compared two methods of local anesthesia for laparotomy in cattle including the modified infiltration anesthesia (MIA) technique consisting of an incision line block combined with an inverted L-block, and the proximal paravertebral anesthesia (PPVA). They concluded that, both techniques required a mean of 8 minutes to complete but the MIA method was considered more difficult than the PPVA. The PPVA required significantly less procaine than the MIA (144 vs. $195 \mathrm{ml}$ ). Comparison of the two techniques with respect to different types of pain reactions (no reaction, non-specific reaction, specific reaction) during cutting of the different layers of the abdominal wall revealed that PPVA provided significantly better analgesia than the MIA. After PPVA, pain reactions to incision of the external oblique abdominal muscle were more severe, but reactions to abdominal exploration and to suturing the two oblique abdominal muscles were significantly milder than after MIA.

In the present study anesthesia of the infraorbital nerve was achieved by injection of $5 \mathrm{ml}$ procaine hydrochloride
$2 \%$ in the vicinity of the infraorbital foramen which was situated $1.5 \mathrm{~cm}$ dorsal to the first cheek tooth and about 6 $\mathrm{cm}$ rostral to the facial tubercle on the same frontal level. The desensitized area comprised the dorsum nasi and diverticulum nasi, the nasal vestibule and superior lip, the maxillary lip, and labial mucous membrane. Edward (2001), Edmondson (2008) and Hussain et al (2009) reported that the infraorbital nerve was the continuation of the maxillary branch of the fifth cranial nerve after it entered the infraorbital canal and emerged on the face as a flat band through the infraorbital foramen where it was covered by the levator nasolabialis muscle The infraorbital nerve was blocked as it emerged from the infraorbital canal. The nerve is difficult to palpate but is located rostral to the facial tuberosity on a line extending from the nasomaxillary notch to the second upper premolar. The latter author added that the infraorbital nerve block may be used for the repair of nasal lacerations and the placement of a nose ring.

In agreement with Park et al (2014) and Jaber et al (2013) the mental nerve was a branch of the mandibular alveolar nerve that emerged via the mental foramen and divided into three branches which are distributed to the skin of the chin and as well as the skin and mucous membrane of the lower 


\section{Regional anesthesia in buffalo}

lip. They added that, the mental nerve block is a simple technique to supply anesthesia to this area and that the lacerations of the lower lip and of the facial soft tissues in the lower chin require proper anesthesia to ensure adequate cosmetic closure. The present study indicated the accurate site for applying the mental nerve block at the middle distance of the lateral surface of the interalveolar space of the mandible between the lateral incisor and first premolar teeth. Mohamed and Fathy (2015) indicated the site of the mental nerve in donkey just rostral to the $1^{\text {st }}$ premolar.

In agreement with Allouch (2014) in bovine and Kataba et al. (2014) in goat, the parameters of the mental foramen were vital landmarks for injection of local anesthetic drugs in the mandibular canal via the mental foramen for blocking the infra-alveolar nerve, so desensitization of the lower jaw with its teeth and the lower lip will be occurred and this method was easier and avoided all risks of blood vessel injures in case of the mandibular alveolar nerve block.

In agreement with Navarre (2006) and Edmondson (2008) in cattle and Prasad et al (2016) in buffalo the cornual nerve block is used for anesthesia for dehorning cattle. The horn and the skin around the base of the horn are
Farag et al.,

innervated by the cornual branch of the lacrimal or zygomaticotemporal nerve, which is part of the ophthalmic division of the trigeminal nerve. The cornual nerve passes through the periorbital tissues dorsally and runs along the frontal crest to the base of the horns. The authors mentioned that the cornual nerve was blocked by injection of the anesthetic drug midway between the lateral canthus of the eye and the base of the horn along the zygomatic process. Similar observations were recorded in the present study that revealed that the cornual nerve in buffalo follows a relatively higher course about $4 \mathrm{~cm}$ medial to the frontal crest. Elmore (1980) added that well-developed horns require additional anesthetic infiltration along the caudal aspect of the horn, in the form of a partial ring block, to desensitize subcutaneous branches of the second cervical nerve.

\section{References}

Allouch, G.M. (2014): Applied anatomy on the maxilla and mandibular regions of the bovine with special reference to its important in regional anesthesia. Int. J. Food, Agricult. Veter. Sci.

Bhatt, P. N. (1999): Buffaloes. In: W.J.A. Payne and R.T. Wilson (authors), an introduction to animal hus- 
Regional anesthesia in buffalo

bandry in the tropics, 5th ed. Blackwell Science, Oxford: 325-404.

Edmondson M.A. (2008): Local and regional anesthesia in cattle. Vet Clin North Am Food AnimPract. Jul; 24(2): 211-26

Edwards B. (2001): Regional anesthesia techniques in cattle. In Pract; 23:142-9

Elmore R.G. (1980): Food animal regional anesthesia, bovine blocks: cornual. Vet Med; 75:1610-2.

Hall, L. W., Clarke, K. W., Trim, C. M. (2001): Veterinary Anesthesia, 10th ed. Saunders, London: 315-339.

Hussain, S.S., Tahseen, L. and Moulvi, B.A. (2009): International Book Distributing co. (Publishing Division) Khushnuma Complex Basement7, MeerabaiMarg (Behind Jawahar Bhawan) Lucknow 226001 u.P. (INDIA): 91-522

Jaber, A, Whitworth, J.M., Corbett, I. P., Al-Baqshi, B., Jauhar, S. and Meechan, J. G. (2013): Effect of Massage on the Efficacy of the Mental and Incisive Nerve Block. Anesth Prog. Spring; 60(1):15-20

Karda, R. T. (1996): Local and regional anesthetic techniques: ruminants and swine. In: Thurmon, J. C,
Farag et al.,

Tranquilli, W. J, Benson, G. J. (Eds.). Lumb \&Jones 'Veterinary Anesthesia, 3rd ed. Williams \& Wilkins,

Baltimore: 479-514

Kataba, A., Edwell, S.M., Humphrey, S., Casanova, P.M. (2014): Clinical anatomy of the head region of Gwembe Valley Dwarf goat in Zambia. Int. J. Veter. Sci., 3(3): 142146.

Lee L. (2006): Local Anesthesia \& Analgesia. Veterinary Surgery I, VMED 7412

Navarre C. (2006): Numbing: nose to tail. Proceedings from the 39th Annual Convention of AABP; 39: 53-5.

\section{Mohamed R.A. and Fathy M.Z.} (2015): Applied anatomy of the head region of donkey (Equus asinus) in Egypt and its clinical value during regional anesthesia. Inter. J. Curr. Res. Aca. Rev. Volume 3 Number 4: 45-58

\section{Nomina Anatomica Veterinaria} (2012): 5th edition Revised version. Prepared by the International Committee on Veterinary Gross Anatomical Nomenclature (I.C.V.G.A.N.) and authorized by the General Assembly of the World Association of Veterinary Anatomists (W.A.V.A.) Knoxville, TN (U.S.A.) 2003 Published by the Editorial Committee Hannover (Germany), 
Columbia, MO (U.S.A.), Ghent (Bel- navia, 83 Supplements. 1:66-79. gium), Sapporo (Japan).

Nuss, K., Eiberle, B.J., Louis, S. C. (2012): [Comparison of two methods of local anesthesia for laparotomy in cattle]. Tierarztl Prax Ausg G Grosstiere Nutztiere. 40(3): 141-9.

Park,H.G., Park,P.G., Kim,W.J., Pa rk, Y.H., Kang, H. Baek, C.W. Jung, Y.H. Woo,Y. C., Koo,G.H. and Shin, H.Y. (2014): Ultrasound-Assisted Mental Nerve Block and Pulsed Radiofrequency Treatment for Intractable Post herpetic Neuralgia: Three Case Studies. Korean J Pain., 27(1): 81-85.

Prasad, V.D. Kumar, P.R. Harikrishna, N.V.V. Sreenu, M. Vidyasagar, P. Mahesh R. and Bhagyaraju, D. (2016): A comprehensive study on surgical affections of horns in buffaloes (Bubalus bubalis). Journal of Livestock Science (ISSN online 22776214) 7: 280-287

Roberts, S. J. (1986): Veterinary Obstetrics and Genital Diseases (Theriogenology), 3rd ed: 294-296.

Shalash, M. R. (1988): The water buffalo of Egypt. Acta Veterinaria Scandi-
Soliman, I. (2009): Present situation and future perspective of buffalo production in Africa. In: Buffaloprospective animals for milk and meat enterprise, 6th Asian Buffalo Congress. Lahore, Pakistan.

Thomas,J. A.and lerche,P.(2016): Anesthesia and Analgesia for Veterinary Technicians, 5th Edition. Columbia, MD, U.S.A

Vermunt, J. (1999): Exploratory laparotomy in cattle. Journal of Veterinary Surgery (IJVS). NZ Vet script 12 (7): 6-7. IRANIAN

Wilson, R.T. (2012): The past and present of and potential for the domestic (water) buffalo in Africa. Trop. Anim. Health Prod. 44: 1367-137.

\section{Corresponding author}

Farag, F.M.M.

Email: fouad.farag@cu.edu.eg 


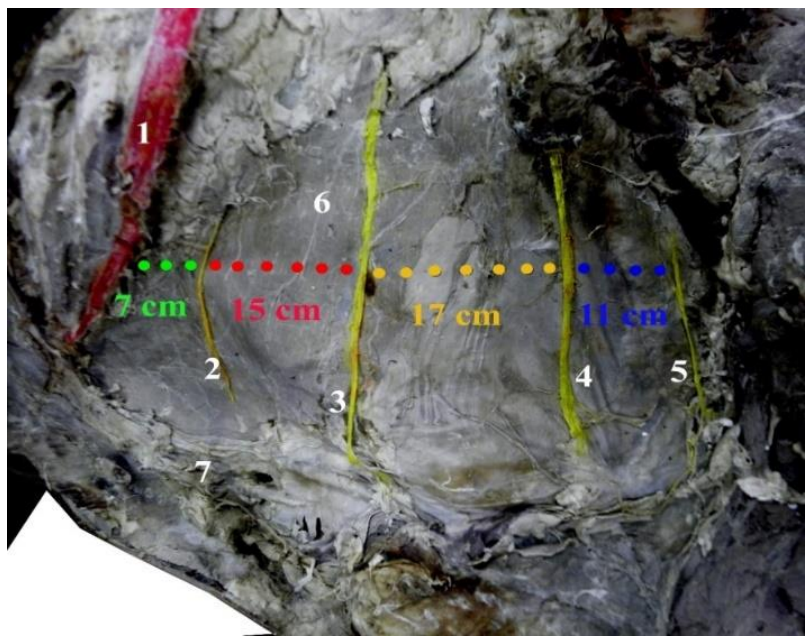

Fig (1): A photograph showing the nerves of the flank region in the buffalo.

$1 \mathrm{~N}$. costoabdominalis, 2 Last rib, $3 \mathrm{~N}$. iliohypogastricus, 4 Tuber coxae, $5 \mathrm{~N}$. Ilioinguinalis, 6 Genitofemoralis, 7 Mammae.

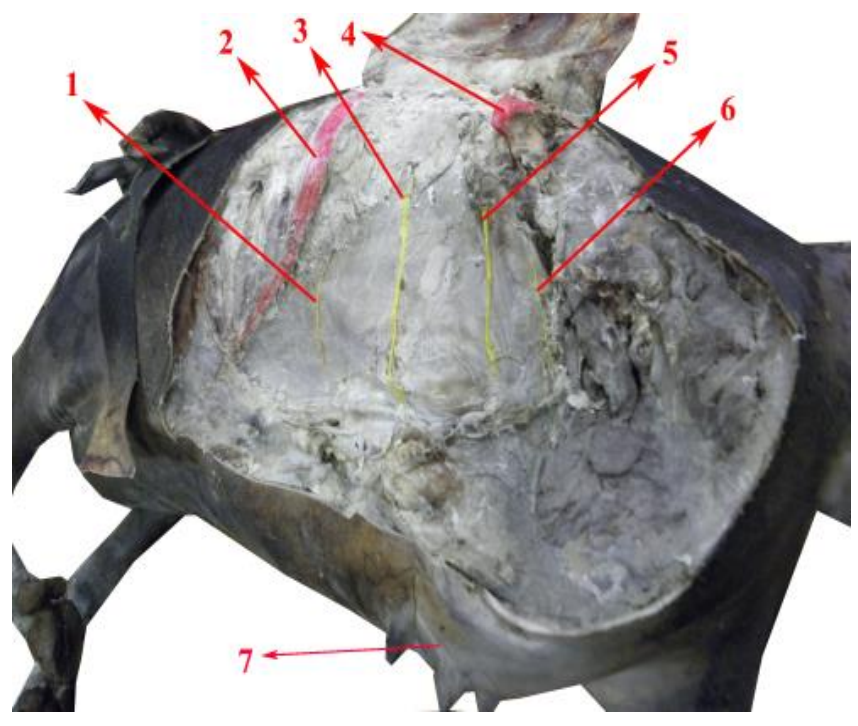

Fig (2): A photograph for a dissected flank of buffalo showing the distance between each nerve.

1 Last rib, $2 \mathrm{~N}$. costoabdominalis, $3 \mathrm{~N}$. iliohypogastricus, $4 \mathrm{~N}$. ilioinguinalis, $5 \mathrm{~N}$. genitofemoralis, $6 \mathrm{M}$. obliquus externus abdominis, $7 \mathrm{M}$. rectus abdominis. 


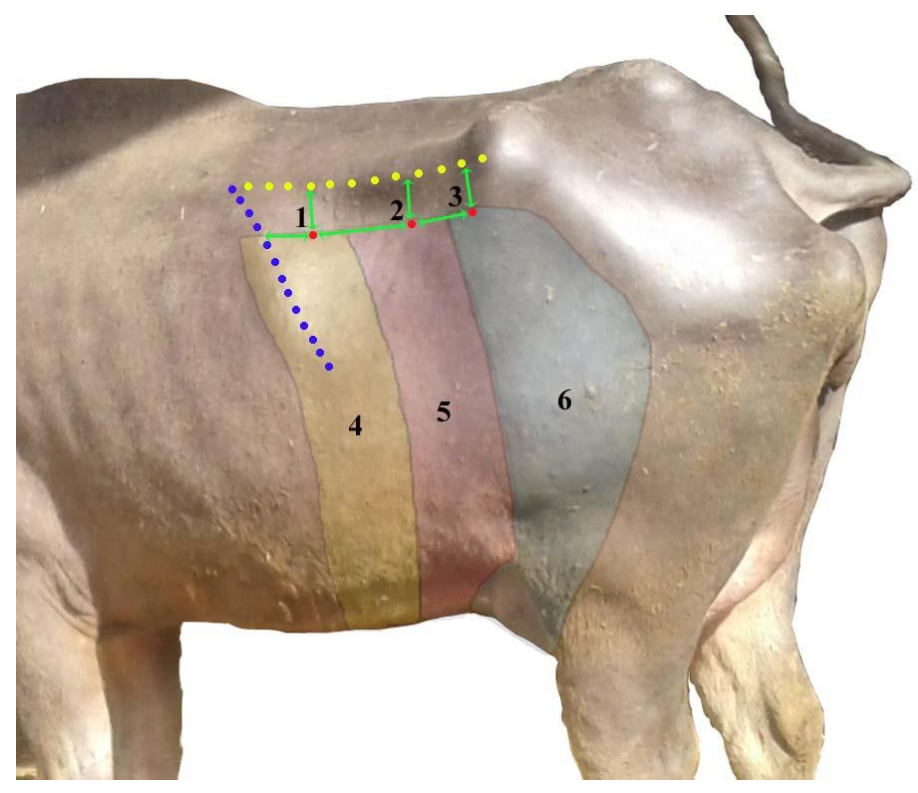

Fig (3): A photograph showing sites of nerve block of each nerve in the flank of buffalo.

1 Site for block of N. costoabdominalis, 2 Site for block of N. iliohypogastricus, 3 Site for block of $\mathrm{N}$. ilioinguinalis, 4 Desensitized area of $\mathrm{N}$. costoabdominalis, 5 Desensitized area of $\mathrm{N}$. iliohypogastricus, 6 Desensitized area of $\mathrm{N}$. ilioinguinalis.

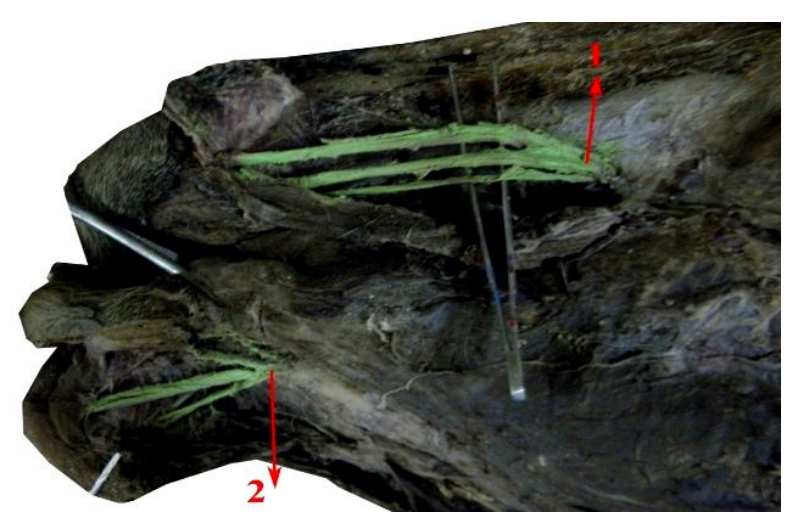

Figure (4): A photograph showing the infraorbital and mental nerve of buffalo.

1. N. infraorbitalis. 2. N. mentalis. 


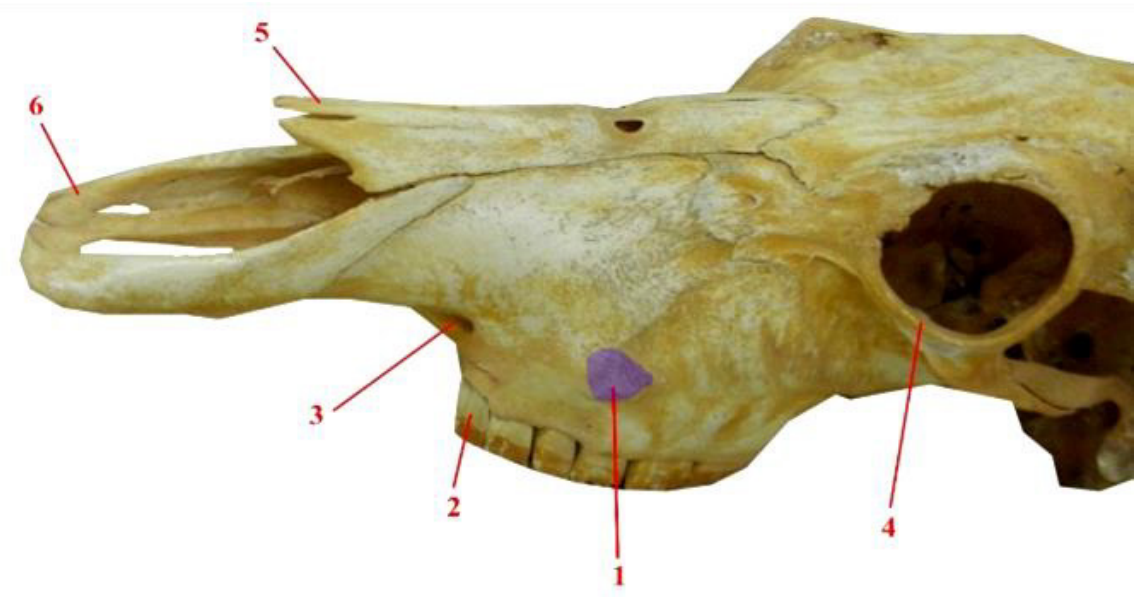

Figure (5): A photograph for the skull of buffalo showing the infraorbital foramen and its relation to the facial tubercle.

1 Tuber faciale, 2 Dentes premolars I, 3 Foramen infraorbitale, 4 Orbital rim, 5 Os nasale, 6 Os incisivum.

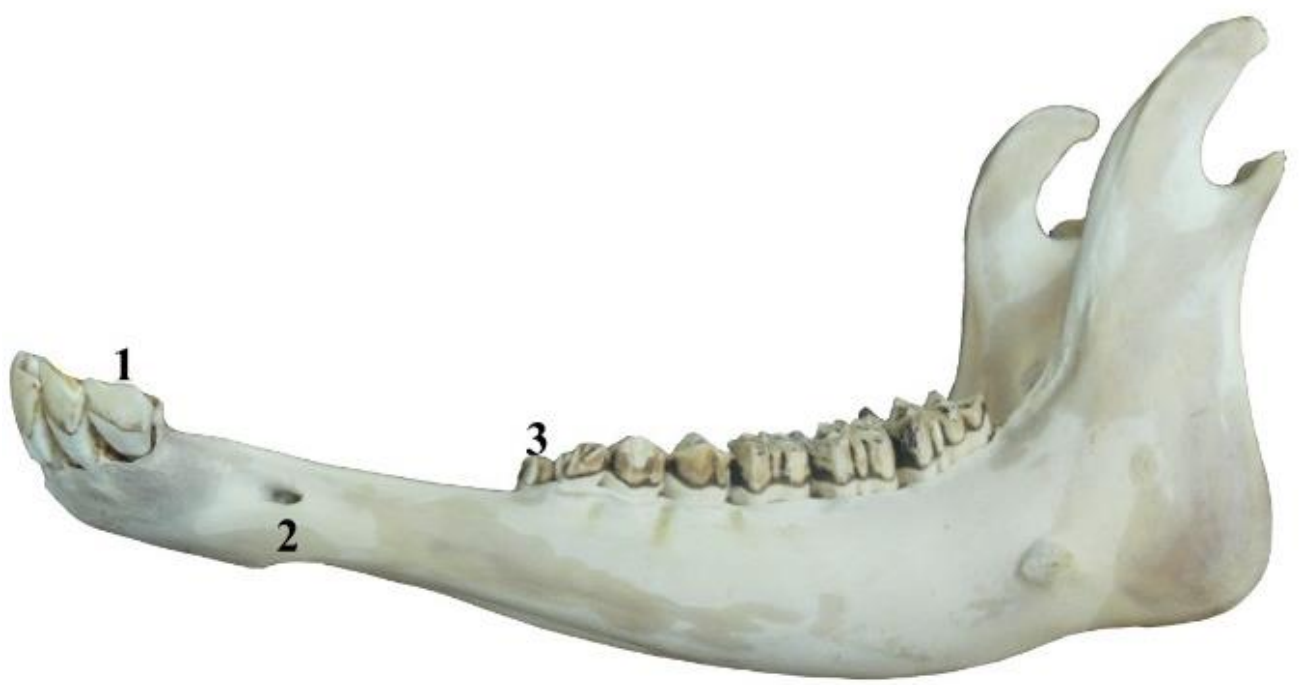

Figure (6): A photograph for the mandible of buffalo showing the mental foramen. 1 Dentes incisivi lateralis, 2 Foramen mentalis, 3 Dentes premolars I. 


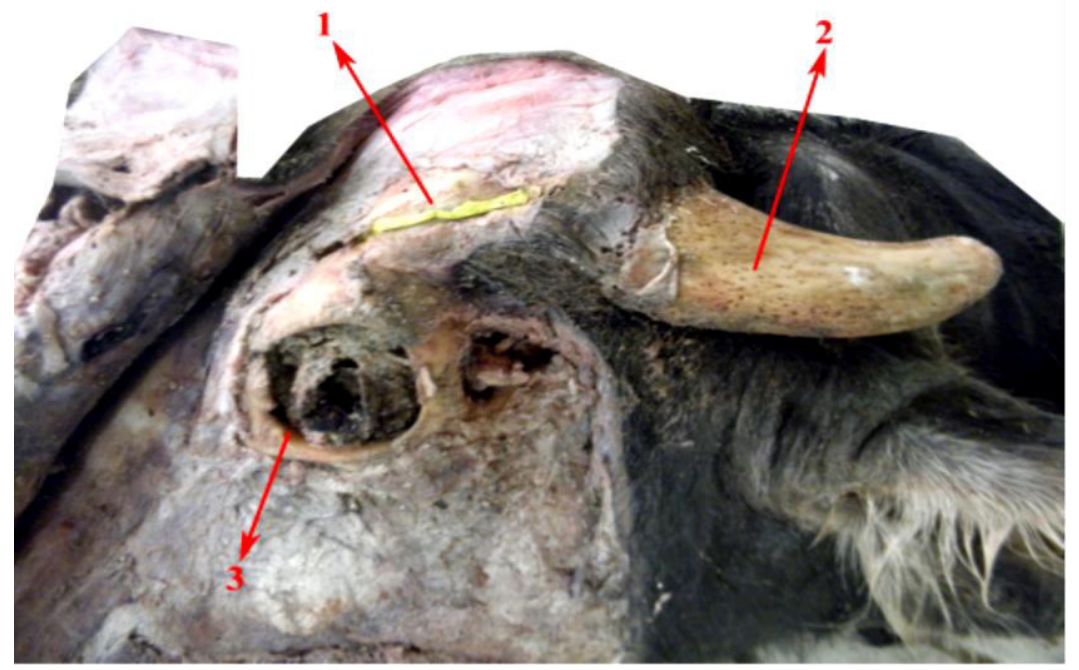

Figure (7): A photograph for a dissected head of buffalo showing the cornual nerve. 1 N. Cornualis, 2 Processus cornualis, 3. Orbital rim

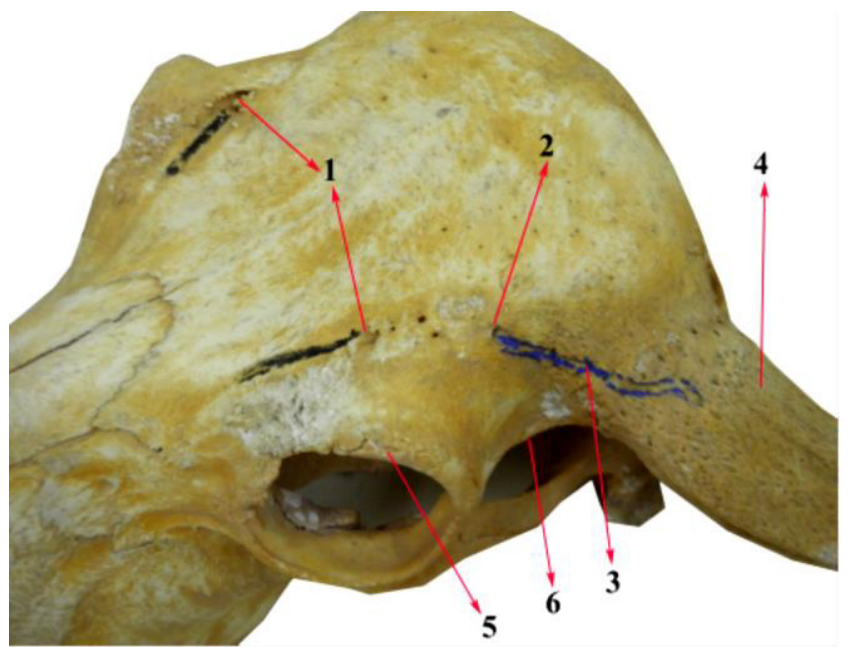

Figure (8): A photograph for the skull of buffalo showing the course of the cornual nerve.

1 Foramen supraorbitalis caudalis, 2 Foramen supraorbitalis rostralis, 3 Groove for $\mathrm{N}$. cornualis, 4 Processus cornualis, 5 Orbital rim, 6 Linea temporalis. 


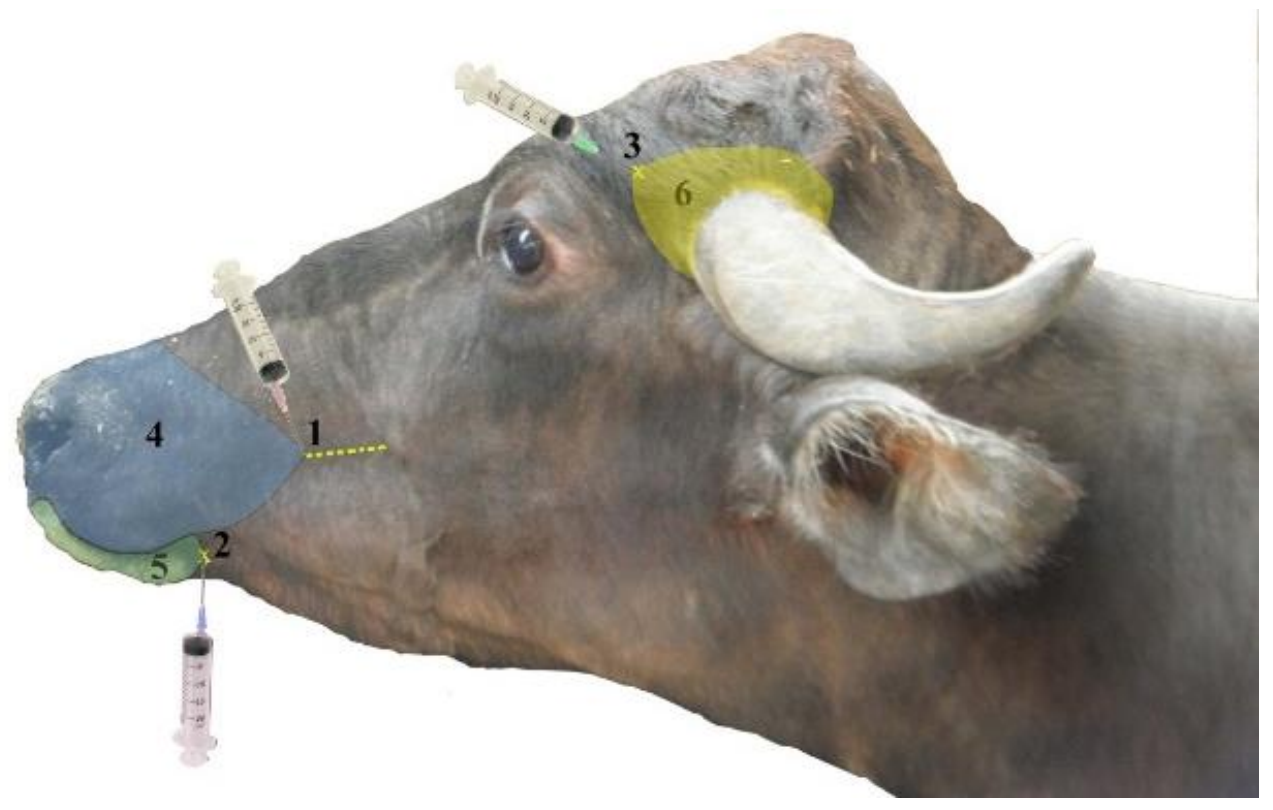

Figure (9): A photograph showing sites of nerve blocks in the head of buffalo. 1 Site for block of $\mathrm{N}$. infraorbitalis, 2 Site for block of N. mentalis, 3 Site for block of $\mathrm{N}$. cornualis, 4 Desensitized area of $\mathrm{N}$. infraorbitalis, 5 Desensitized area of N. mentalis, 6 Desensitized area of $\mathrm{N}$. cornualis. 


\section{Animal species of this issue}

\section{Water buffalo (Bubalus bubalis)}

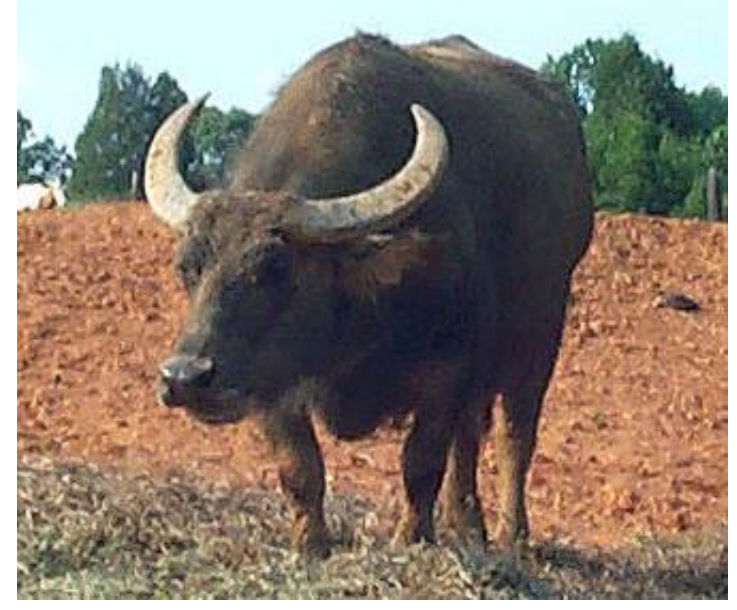

Kingdom: Animalia \& Phylum: Chordata \& Class: Mammalia \& Order: Artiodactyla \& \& Family: Bovidae \& Subfamily: Bovinae \& Tribe: Bovini \& Genus: Bubalus \& Species: B. bubalis

The water buffalo or domestic Asian water buffalo (Bubalus bubalis) is a large bovine animal, frequently used as livestock in southern Asia, and also widely in South America, southern Europe, north Africa, and elsewhere.

Buffalo are used as draft, meat, and dairy animals. Their dung is used as a fertilizer and as a fuel when dried. In Chonburi, Thailand, and in South western region of Karnataka, India, there are annual water buffalo races known as Kambala. A few have also found use as pack animals carrying loads even for special forces.

Adult Water Buffalo range in size from 400 to $900 \mathrm{~kg}$ for the domestic breeds, while the wild animals are nearly $3 \mathrm{~m}$ long and $2 \mathrm{~m}$ tall, weighing up to 1,200 kg; females are about two-thirds this size.

River buffalo are usually black and have long curled horns, whereas swamp buffalo can be black or white, or both, with gently curved horns. The largest recorded horns are just under 2 metres long.

Source: Wikipedia, the free encyclopaedia 